\title{
The Role of the Corporate Multilateral Agencies in Education: The Case of Literacy Projects in Tanzania
}

\author{
Anyanzo John Philip \\ Aga Khan University, Institute for Educational Development, East Africa
}

How to cite this paper: Philip, A., J. (2017). The Role of The Corporate Multilateral Agencies in Education: The Case of Literacy Projects in Tanzania.The Educational Review, USA, 1(2), 17-25.

http://dx.doi.org/10.26855/er.2017.02.001

Corresponding author: Anyanzo John Philip, Master of Education Student, Aga Khan University, Institute for Educational Development, East Africa (AKU-IED).

\begin{abstract}
This paper reports on the review of selected literacy projects in Tanzania funded through the support of Corporate Multilateral Agencies. The world conferences on education for all which resulted into the Millennium Development Goals (MDGs) challenged African governments to focus on access, equity, and quality education for all. Consequently, many African governments over the last decade invested hugely in education resulting into many more children accessing basic education than ever before. In Tanzania, the 1995 and 2014 Education and Training policies with emphasis on quality education, and the introduction of fee free basic education provision are consistent with the global agenda such as United Nations Sustainable Development Goals (SDGs). However, despite the numerical and infrastructural achievements in education in Tanzania, several study reports have continued to show low learning outcomes especially in basic literacy and numeracy among Tanzanian children. Therefore, given the limitations of the government in delivering quality education and providing sustainable solutions to literacy challenges in Tanzania, this paper implores that, the Corporate Multilateral Agencies play a crucial role in offering sustainable solutions to the literacy achievement crisis by either direct funding of the projects or mobilizing others to navigate different types of literacy innovation projects. Findings from the review suggest that, reading instruction, culture and learning outcomes of primary school children have improved as a result of the literacy projects which exposed children to grade level and age appropriate reading resources. However, sustainability of the projects, policy gaps, and ideological differences of multilateral agencies stand out as challenges facing the literacy projects. This paper recommends that, the Ministry of Education and Training should streamline, and coordinate any literacy projects funded by multilateral agencies, scale up the innovations and with time integrate literacy innovations in to national curriculum, plans and budgets for sustained results, and replication of best practices.
\end{abstract}

\section{Keywords}

Corporate Multilateral Agencies, literacy, sustainability, policies, Millennium Development Goals (MDGs), Sustainable Development Goals (SDGs)

\section{Introduction}

The International Community has supported an unprecedented increase and access to basic education over the last decade. The world conferences on education in 1999 and 2000 resulted into the Education for All (EFA) and Millennium Development Goals (MDGs) (Mundy, Green, Lingard, \& Verger, 2016). MDGs are a set of time-bound, measurable goals that targets among other thematic areas combating illiteracy by 2015. Goal two of the MDGs challenged African governments to ensure that by 
2015, all children have access to, and complete free and compulsory primary education of good quality. However, the MDGs have been replaced by the United Nations Sustainable Development Goals (SDGs) 2030 which took effect in January, 2016. Goal number four (4) of the SDGs 2030 aims to "ensure inclusive and equitable quality education and promote life-long learning opportunities for all". Therefore, the huge investments by the past and present Tanzanian governments in education have been a response to the demands of providing education for all. Consequently, the introduction of fee free basic education early this year, Education and Training policies (ETP) of 1995 and 2014 respectively are consistent with the global agenda. In addition, government increased funding for school infrastructural developments and teacher education in a bid to address quality education. This has enabled government to meet its targets, and International demand of increasing access and equity to formal basic education.

However, despite the increased access to basic education, infrastructural developments and education policies, quality education remains an underachieved phenomenon. Study reports continue to indicate persistent low learning outcomes of the learner cohorts enrolled. According to UNECSO ( 2015), 40\% of second graders could not read a word in Kiswahili while three out of ten in standard three could read a standard two text (UWEZO, 2015). Thus, this state of affairs stimulates a fresh concern in an era of globalization because quality education is pre-requisite, and foundation for individual and societal socio-economic development. This paper posits that, learning outcomes increase with increased competences in literacy and numeracy. Literacy development, therefore, becomes a crucial tool for acquiring a wide range of learning skills and acts as an inducement for everyday life and life-long learning. Besides, literacy is one of the pillars that support individual and societal development as well as playing a key role in poverty reduction. Ngwaru and Oluga (2015) assert that, there is no ground to dispute the close correlation existing between poverty and illiteracy. The rate of literacy is conversely proportional to the rate of poverty, that is, the lower the literacy rates, the higher the poverty rates and vice-versa. This suggests that, a literate population is productive and can support social, economic and political development of a developing country like Tanzania in an era of globalization.

In this paper, literacy is viewed in the broadest context and described as the ability to recognise, comprehend, infer, create, compute, and communicate using visual, audible and digital materials across disciplines, socio-cultural and other contexts (Otto, 2008), International Literacy Association, 2016). The purpose of this paper was to present the contributions made by Corporate Multilateral Agencies over the last decade in literacy enhancement in Tanzania. This paper describes multilateral agencies as international organisations or institutions with three or more governmental membership which conduct all or a significant part of their activities together in favour of development, in aid recipient countries. These corporate multilateral agencies include but not limited to:

- United Nations agencies such as; United Nations Education, Scientific and Cultural Organisation (UNESCO), United Nations International Children Education Fund (UNICEF), United Nations Development Programme (UNDP), and United Nations High Commission for Refugees (UNHCR).

- Financial institutions (Banks) such as; World Bank (WB), African Development Bank (ADB), Asian Development Bank (ADB), and International Monetary Fund (IMF).

- European Union Institutions such as; Irish Aid, Netherlands Royal Embassy, Swedish government, Belgium Technical Corporation (BTC), European Development Fund (EDF).

- Development agencies such as; Aga Khan Development Network (AKDN), Global Affairs Canada, and United States Agency for International Development (USAID).

- Non-Governmental Organizations (NGOs) such as; World Vision, Save the Children, Compassion International, and Plan International.

- Business firms such as; Coca Cola, Vodacom, Airtel, and MTN.

- Regional bodies. 
It is premised that, this paper could invoke further commitments of multilateral agencies and government of Tanzania to consolidate, and sustain existing literacy innovations. In addition, the multilateral agencies can play a pivotal role in funding the literacy projects. In this way the current literacy achievements crisis can be addressed by offering more opportunities and strategies for sustainable improvement of learning outcomes of Tanzanian children.

\subsection{Purpose of the Study}

The purpose of the review was to explore the extent to which Literacy projects implemented through the support of Corporate Multilateral agencies have changed the fortunes of learning outcomes in Tanzanian schools. This was intended to recognize the efforts of multilateral agencies in supplementing governments in achieving educational agenda in an era of globalization. Additionally, the paper sought to stimulate both local and global efforts in strengthening literacy enhancement projects.

\subsection{Research Questions}

The study sought to answer the following questions:

i. How are Literacy projects initiated by Corporate Multilateral agencies contributing to literacy enhancement in Tanzania in an era of globalization?

ii. What are the challenges facing the implementation of donor funded literacy projects in Tanzania?

iii. What are the strategies that have been put in place by the Corporate Multilateral agencies and government of Tanzania to sustain the literacy projects?

\section{Methodology}

\subsection{Overall Design}

The overall design for this review was an intrinsic case study. According to Pine (2009), an intrinsic case study describes a specific situation and understands an inner working to afford the wholistic entity.

A case study can be a person, organization or phenomena. However, the focus of this review was on the organisations (multilateral agencies) supporting or funding literacy projects (phenomena). Based on my background as a Language educator, Project Officer of a Donor funded literacy project, and specialist in Language and literacy, I adopted an intrinsic case study design to enable me illuminate meaning through in-depth analysis of literacy projects implemented through the support of multilateral agencies. Although a basic characteristic of case study is that of using a number of different data sources (Yin, 2003), the review focused more on document analysis, field experiences, and unstructured interview with two education partners.

\subsection{Selection of the Literacy Projects for Review}

The projects' documents for review were selected purposively on the basis of their focus on literacy enhancement either by direct provision of reading materials or space for primary school children or indirectly through enhancing the competences of teachers in literacy instruction. The second criterion used was to select literacy projects that targeted primary school children. Although some of the libraries were established for all levels of learners, data was limited to primary school children.

\subsection{Analysis}

The findings of this paper emerged from secondary data which involved an extensive review and triangulated evaluation reports, project reports, and project books reviewed. I analysed in details the nature, purpose, achievements, and challenges of selected literacy projects. According to Dowling, Brown, and Brown (2010), documents are rich sources of data. I then compiled and described experiences that can be drawn, lessons that can be learnt from the literacy projects, and finally wrote memos to the main findings. The main purpose was to share the findings to inform policy and practice in Tanzania in the Era 
of Globalization. The themes were created by identifying common issues that emerged from the projects, and those that needed stakeholder's attention and intervention.

\section{Review and Analysis of the Selected Literacy Projects}

\subsection{Readership Promotion Experiences in Tanzania: The Tusome Vitabu Project}

The Tusome Vitabu project was funded by the Netherlands Royal Embassy, and implemented by Cooperative for Assistance and Relief Everywhere (CARE) International, Tanzania between 1999 and 2006. The project was implemented in 16 districts covering the regions of Arusha, Kagera and Mwanza (Okwach \& Sifuna, 2007). The purpose of the project was to promote reading habits among primary pupils by providing reading materials, and increasing access to reading materials, and creating conducive reading environment for sustainability.

Overall, the project led to participation of pupils in their learning, community engagement in management, formation of clubs, establishing 676 functional libraries, 680 library sub-committees, and training of about 1120 teachers. As a result, the teaching and learning process was promoted, leading to improved academic performance of primary children. However, the project had challenges of readership time, economic capacity of community members to organize reading days and competitions, documentation, and monitoring (Onukaogu, Parry, \& International Reading Association, 2005).

\subsection{The Lakeside literacy in Tanzania: The Katoke School Improvement Project}

The project was implemented in 2003, and based at a Teachers' College south of Bukoba in the Kagera Region. The project was a link between University of New South Wales in Sydney, Australia, and Katoke Teachers' Colle ge in partnership with UNICEF. The project aimed at strengthening quality of teaching and learning in 20 surrounding primary schools and for improving their poor quality of education by then. More so, the project was aimed at supporting the Tanzanian Education and Training policy (ETP) of 1995. Therefore, its emphasis on quality education was consistent with the 2002 Primary Education Development Plan (Babyegeya, 2002).

Through its six strands of leadership strengthening, community involvement, peer supervision, scholarship, resources, and teaching, the project improved quality of education in the beneficiary schools.

\subsection{Reading for All: Movement to Mainstream Active Learning Approaches in Tanzania}

The project aimed at changing the face of reading instruction in order to promote literacy skills in Tanzania. This was a partnership between the Ministry of Education and culture, UNESCO, and International Reading Association (IRA). The project was organized under UNICEF-UNESCO and Tanzania government to build capacity of professional teachers in subject areas. For example, there was in-service training on reading, writing and arithmetic (3Rs). In 1981 through the support from Swedish government, the methodology was institutionalized in Korogwe Teachers' Training College and schools.

\subsection{Children's Book Project, Tanzania (CBP)}

The project was founded in 1991 as a readership intervention programme to develop literacy skills amongst school children and youth. The project operated in 13 districts of Coastal and rural districts close to Dar es Salaam. The project encouraged reading culture among children by increasing access to quality books for teachers, pupils and youth. Additionally, the project enhanced teacher pedagogical competences to improve quality reading and writing instruction.

Internal evaluation report showed that literacy development was strengthened through provision of socio-cultural sensitive and grade level reading books. More so, there was increased student and teacher achievement (Misty, James, \& Dennis, 2009). 


\subsection{Room to Read (RtR)}

Room to read operates in nine countries in Asia and Africa. In Tanzania, activities, along with programme implementation began in 2012. Consistent with its model of wholistic intervention, RtR launched School Library, teacher empowerment, school construction and Girls' Education programmes in partnership with the local government, Aga Khan University-Institute for Educational Development, East Africa and individual communities. As a result, 51 libraries were established, 31 book titles published, 48 school construction projects completed and 888 Girls' Education participants were empowered to remain in school. This increased the retention of girls in school as a result of life skill training. Again, improved teaching methodology of teachers had been enhanced through on-going support (Annual report, 2014).

Furthermore, responding to the demands of Millennium Summit held in New York 2000, RtR through its theory of change deliberately focused on literacy development. Consequently, there was increased access to culturally relevant, age-appropriate and gender-sensitive reading materials. Children have become independent readers, thus empowering them for life-long learning. RtR has been able to achieve this by increasing the effectiveness of teachers and facilitators to teach literacy skills and develop the habit of reading among children.

Additionally, RtR improved the infrastructures of schools and addressed the need for better learning environments with adequate space-creation of a literate environment at school and home. A study by Ngwaru and Oluga (2015) indicated that, school infrastructures are important to sustainable access to schooling and educational outcomes. Therefore, adequate infrastructures with adequate, relevant, creative, socio-cultural sensitive and interesting print materials encourage and foster a culture of reading. According to annual report of 2014, children have become independent readers as a result of reading culture inculcated through the provision of the reading materials.

\section{Findings and Discussion}

In this sub-section, I present and discuss the findings of the review under various themes:

\subsection{Promotion of Reading Culture and Literacy Development}

Findings from the review indicate that, the literacy projects have exposed primary school children to a variety of reading materials especially books. For example, the libraries established under the RtR programme and the Tusome Vitabu project offered more opportunities for readership, hence, inculcated the culture of reading for both pleasure and information among children. The evaluation report on Vitabu project (2007) and annual report on RtR (2014) revealed improvement in literacy development and learning outcomes. More so, the libraries successfully connected oral and written culture, and thereby stimulated the interest of reading among children. The evaluation report of the Vitabu project further indicated a change in the literacy practices of at least some of the children in the local community. These findings are therefore, consistent with the ideological view of literacy that describes literacy as always context bound, situated in culture and time/space (Kozulin, 1998). Additionally, Street (2001) affirms this finding and persuades that, if any literacy projects and programmes are to be effective in diverse regions of the world, researchers need to understand the uses and meanings of literacy practices to local people themselves.

\subsection{Teacher Professional Development}

The review established that teachers' pedagogical and professional development progressed hand in hand with the implementation of the literacy projects. The literacy projects reviewed had pedagogical components for enhancing teachers' capacity in thematic and need based areas. The practice was vital and good strategy for sustainability and institutionalization because teachers are frontline implementers of the project activities. In addition, the quality of literacy instruction depends on quality of teachers' competences in implementation and delivery of project activities. For example, in-service training on the 3Rs, peer 
supervision, and methodology are consistent with teacher pedagogical improvements. In line with teacher pedagogy, Markee (1997) argues that " teachers' pedagogical choices cannot be made simply on the basis of abstract principles written in the curriculum or textbooks, but need to accommodate the realities of each teaching situation in its own right"(p.397). Markee continues to make a case that, teachers must perceive change to be relatively advantageous to them if they are to accept. For teachers to own an innovation, they need to be given the opportunity to clarify their ideologies and ideas. However, most of the projects are introduced to teachers without initial engagement. As such, they implement the project activities mechanically with little creativity, and behavioural change. This is what has turned out to be detrimental to the effectiveness of most of the literacy innovations.

\subsection{Institutionalization and Integration}

Based on two of the projects reviewed, the review found that the interventions were integrated in to Teachers' Training Colleges. This was a very strategic arrangement because institutionalizing the interventions ensures replicability, sustainability, and ownership. Hall and Hewings (2001) observe that, for people to be persuaded to adopt an innovation, the innovation should be rationalized in their self-interest. Therefore, integrating literacy innovations into teacher training curriculum could rationally influence acceptance. However, the ministry of Education and Training needs to streamline all the interventions, and recommend an innovation that will stand the test of time in changing the fortunes of learning outcomes in Tanzania. This is because of the diverse and technical nature of literacy innovations initiated by the multilateral agencies.

\subsection{Community Engagement and Local Partnerships}

The review recognizes the strategies of the different organisations in engaging with universities, government, and communities. The universities harness technical and professional support, communities mobilise local resources, while government provides oversight in terms of monitoring, and supervision. According to Irvin (2010), community involvement in supporting literacy activities at the school can enhance the schools' literacy programme by supporting the success of literacy improvement efforts through regular two-way communication and sponsorship of literacy related activities. Onukaogu et al (2005) further commends that careful planning and community support to libraries could be a wonderful resource for children and their parents. This can encourage parental participation in education of their children like joint parents and children reading sessions as in the Tusome Vitabu project.

Relatedly, the community libraries empowered community members to improve their livelihoods by being exposed to books related to their economic activities. For example, the Tusome Vitabu Project motivated some community members to borrow and read books related to their social wellbeing like health, family planning, and economic activities such as farming. The findings relate to Asselin and Doiron (2016) study who found that village libraries are strategically positioned in the ways their programmes and activities are interwoven with schools, adult education, health, women, family and youth organisations. The libraries connect to community values and uplift quality of life as the knowledge and skills acquired from reading the books are applied in the day to day economic activities. This is a holistic nature of education provided by the libraries which is important for socio-economic development. Similarly, the Children's Book Project (CBP) ensured that teachers and students had access to books that reflect Tanzanian culture and experiences. In this way, the mission of education is achieved.

\subsection{School Infrastructural Developments}

The review indicated that, libraries were constructed leading to improvement of school facilities in the beneficiary communities. During the evaluation of the Tusome Vitabu project in 2007, functional libraries were found to have increased from $10 \%$ to $96 \%$. In addition, $97 \%$ of school libraries visited had established proper library lending services. Use of libraries was further 
included in the official school timetable. This made reading materials, both reference and readers accessible to learners and led to a remarkable reduction in the textbook-pupil ratio. Therefore, investing in hard ware does not only guarantee sustainability but also continue to provide a literacy rich environment especially for the rural poor, and resource constrained communities. For example, in Bukoba and Muleba districts, school stakeholders had to construct reading huts to cope with the challenge of reading space. Hence, constructing school libraries provided opportunities to enhance literacy activities support educational, and learning within a unique social context as noted by Dent, Goodman, and Kevane (2014). Indeed, schools have unique social challenges which were addressed through the interventions.

\section{Main Challenges, Conclusion and Recommendations}

\subsection{Challenges}

Sustainability

The findings reveal inadequate strategies for making school libraries and readership activities part of the whole primary school development and classroom teaching-learning activities. The cenralisation of project activities by government means inadequate local control, participation and diversity. This made it difficult to sustain the projects as local communities could not contribute materially and technically in terms of project delivery. For example, if communities contribute towards the procurement of more books/readers, construct more reading space and participate in meetings, they own the projects. Therefore, the lack of genuine coordination at the global and country level that makes it hard for multilateral donors to fill all financial gaps (Benavot \& UNESCO, 2015), (Pauline, Liesbet, Katie, \& Asma, 2013) . Government and Community participation and contributions would have filled such gaps.

\section{Replication of Best Practices}

None of the projects reviewed covered the whole country. For example, the Children Book project (CBP) 13 districts only while the Tusome Vitabu project covered 16 districts. This means that many Tanzanian children are left out in such interventions. In addition, these projects did not have clear strategies for replication. For example, while most classrooms in Tanzanian schools under the Children Book project had bare walls, the CBP programme schools were filled with stimulating learning materials and innovative child-friendly learning aids. These projects ended at pilot stage, and the government is expected to take it up despite limited resources. However, the replication should be based on the efficacy of methodology of the intervention, practical application in different contexts, and current conceptualization in order to yield similar or better desired results (Coyne, Little, Rawlinson, Simmons, Kwok, Kim, Civetti, 2013)

Impact of Interventions

The evaluation reports and documents on the literacy interventions are not clear on the extent to which literacy or learning has improved. If there is improvement, what is the extent of improvement or performance? Is it by 5\% or $10 \%$ ? This is not made clear to stakeholders apart from general statements such as; literacy has improved or learners' performance has improved. Additionally, learning outcomes of pupils improve according to the level of implementation and uptake of the literacy projects. The uptake largely depends on the in-puts and efficacy in executing project activities. For example, the evaluation report of the Children's Book project (2012) indicated that the more a school implements, the higher a teacher's rating on active teaching. Additionally, the report highlighted that, there was no statistically significant differences between intervention and control schools on the teacher and text variables in May 2009.

Philosophical and Ideological Differences 
The multilateral agencies sometimes set conditions which are difficult to comply with. Beneficiaries are expected to demonstrate practices that conform to requirements of donor agencies in order to get financial support for projects such as good governance. More so, there has been a recent demand to comply with national and international norms on environmental and self-regulations (Vives, 2004). Similarly, the agencies have their own philosophical differences which sometimes constitute conflict of roles, loyalty and trust for implementers, and local experts. The multilateral agencies have different models which in most cases are not coordinated. For example, under the Tusome Vitabu project, books were directly procured from sellers some of whom were non-registered book sellers while under the CBP; books provided were locally made to focus on local culture.

\subsection{Conclusion}

The role of the Corporate Multilateral Agencies in offering opportunities for sustainable improvement of learning outcomes of Tanzanian children is evident, recognized, and important. Despite unique difficulties met by the literacy interventions, they have been marked on the whole by some achievements in promoting reading culture by providing readers. However, the literacy interventions remain short term alternatives to literacy development. Therefore, this paper makes a strong appeal to the Corporate Multilateral Agencies, Tanzanian government, and communities to support, sustain and institutionalize the literacy innovations to keep pace with the 2030 agenda of ensuring equitable, inclusive and quality education as well a vision 2025 .

\subsection{Recommendations for Policy and Practice}

To consolidate, increase and sustain achievements of literacy projects initiated or supported by Corporate Multilateral Agencies, I recommend that:

The government through the Ministry of Education and Training should decentralize project management to ensure that beneficiary communities, schools and key duty bearers in education own the projects. The role of central government should be that to provide logistic and technical support. In this way, the habits, attitudes and perceptions of all stakeholders and local communities regarding the literacy innovations can be changed. This helps to create sense of ownership, promote participation, control of the projects, and thus, promote sustainability of the projects.

Government of Tanzania through the Ministry of Education and Training should streamline and coordinate the different literacy interventions with possibility of integrating best models into the national curriculum, especially teacher education curriculum, government plans, and budget. In this way, best practices can be replicated and scaled up to the whole country.

The philosophy of education in Tanzania since Education and Training policy 1995 is "Education for self-reliance". This philosophy guides the planning and practice of education activities and ensures that theory is translated into practice. Therefore, the government of Tanzania should ensure that the multilateral agencies are guided by the philosophy in order to reflect the country's values, aspirations, and principles. This helps both local and international experts to operate in conflict free environment in terms of offering expertise and relevance related to the donor funded literacy projects.

Local and District Education departments should create awareness by sensitising beneficiary communities about the importance of the Literacy projects in enhancing Literacy development. Such awareness makes the stakeholders informed and demonstrates commitment and accountability in the implementation of the project activities. For any change initiative to thri ve, the stakeholders and education leaders at both national and local levels should be well informed for the purpose of buy-ins so that they offer quality support, mentorship and supervision of the project activities.

At school level, teachers are in most cases the principle implementers of project activities. Therefore, to ensure the project activities are integrated into classroom teaching and learning, the implementing agencies and education stakeholders should encourage and strengthen teachers to form network of teachers to enable them share classroom and school based micro innova- 
tions in teaching and learning such as; managing large classes, using learner centred pedagogy, and improving learner performance. This is because of different levels of expertise, implementation, and uptake regarding the literacy projects.

The main limitation of this paper was its design which focused more on review of project report, documents, and relevant books with limited field work. Although the reviewer has in-depth knowledge drawn from similar studies in both Tanzanian and Ugandan context, there is need for more persuasive findings and argument in relation to this sub-theme. Hence, future studies could utilize both primary and secondary data collected from intervention sites, and research beneficiaries, as this is an area of interest in an era of globalization.

\section{References}

Asselin, M., \& Doiron, R. (2016). Linking Literacy and Libraries in Global Communities. London; New York: Routledge.

Benavot, A., \& UNESCO (Eds.). (2015). Achievments and Challenges (1. ed). Paris: Unesco Publ.

Coyne, M. D., Little, M., Rawlinson, D., Simmons, D., Kwok, O., Kim, M., \& Civetelli, C. (2013). Replicating the Impact of a Supplemental Beginning Reading Intervention: The Role of Instructional Context. Journal of Research on Educational Effectiveness, 6(1), 1-23. https://doi.org/10.1080/19345747.2012.706694

Dent, V. F., Goodman, G., \& Kevane, M. (2014). Rural Community Libraries in Africa: Challenges and Impacts. Hershey, PA: Information Science Reference.

Dowling, P., Brown, A., \& Brown, A. (2010). Doing Research/Reading Research: Re-interrogating Education (2nd ed). London; New York: Routledge.

Hall, D. R., \& Hewings, A. (Eds.). (2001). Innovation in English Language Teaching: A Reader. London ; New York: Routledge in Association with Macquarie University and The Open University.

Irvin, J. L. (Ed.). (2010). Taking the Lead on Adolescent Literacy: Action Steps for School Wide Success. Thousand Oaks, Calif. : [Newark, Del.]: Corwin Press ; International Reading Association.

Kozulin, A. (1998). Psychological Tools: A Sociocultural Approach to Education. Cambridge, Mass.: Harvard University Press.

Markee, N. (1997). Managing Curricular Innovation. Cambridge [England] ; New York: Cambridge University Press.

Misty, S., James, V. H., \& Dennis, D. (2009). Summary Report on the Internal Evaluation, Children's Book Project. Tanzania.

Mundy, K. E., Green, A., Lingard, B., \& Verger, A. (2016). The Handbook of Global Education Policy. Accessed from http://search.ebscohost.com/login.$a s p x$ ?direct=true \&scope=site \&db=nlebk\&db=nlabk\&AN=1193817.

Ngwaru, J. M., \& Oluga, M. (2015). Educational Infrastructure and Resources for Sustainable Access to Schooling and Outcomes: The Case of Early Literacy Development in Southern Tanzania. Africa Education Review, 12(1), 88-108. https://doi.org/10.1080/18146627.2015.1036570

Okwach, A., \& Sifuna, D. (2007). The Final Evaluation of Tusome Vitabu Project. Dares Salaam, Tanzania.

Onukaogu, C. E., Parry, K., \& International Reading Association (Eds.). (2005). Literacy for all in Africa. Kampala: International Reading Association.

Otto, B. (2008). Literacy Development in Early Childhood: Reflective Teaching for Birth to Age Eight. Upper Saddle River, N.J: Pearson/Merrill Prentice Hall.

Pauline, R., Liesbet, S., Katie, S., \& Asma, Z. (2013). Financing for Global Education: Opportunities for Multilateral Action.

Pine, G. J. (2009). Teacher Action Research: Building Knowledge Democracies. Los Angeles: Sage.

Street, B. V. (Ed.). (2001). Literacy and Development: Ethnographic Perspectives. London ; New York: Routledge.

Vives, A. (2004). The Role of Multilateral Development Institutions in Fostering Corporate Social Responsibility. Development, 47(S3), 45-52. https://doi.org/10.1057/palgrave.development. 1100065

Yin, R. K. (2003). Case Study Research: Design and Methods (3rd ed). Thousand Oaks, Calif: Sage Publications. 